\title{
Enfrentamento e Regulação Emocional de Crianças Filhas de Mães Depressivas ${ }^{1}$
}

\author{
Juliana Lopes \\ Sonia Regina Loureiro \\ Universidade de São Paulo
}

\begin{abstract}
RESUMO
Objetivou-se comparar eventos de vida (EV) negativos, as estratégias de enfrentamento e de regulação emocional relatadas por crianças que convivem com a depressão materna, em comparação a crianças que convivem com mães sem história psiquiátrica. Participaram do estudo 40 crianças, ambos os sexos, com idades entre 7 e 12 anos e nível intelectual pelo menos médio, distribuídas em dois grupos: G1- Depressão materna; G2- Sem história psiquiátrica. Procedeu-se à avaliação individual por meio do Raven e da Entrevista de Eventos Vitais Negativos. As entrevistas foram transcritas e as estratégias de enfrentamento e de regulação emocional classificadas por duas avaliadoras independentes (concordâncias de 0.81 e 0.89 , respectivamente), tendo por base categorias previamente definidas. Os dados foram comparados por meio do teste $U$ de Mann-Whitney $(\mathrm{p} \leq 0,05)$. Os grupos não diferiram quanto aos eventos e enfrentamento frente aos estressores relativos a doenças e acidentes. Observouse maior utilização da espera passiva por parte de G1 como estratégia de regulação emocional frente a eventos do cotidiano. A análise dos dados mostrou que as experiências de vida são semelhantes e frente aos EV negativos, caracterizou-se o esforço adaptativo das crianças que convivem com a depressão materna para o enfrentamento dos estressores.

Palavras-chave: enfrentamento; eventos de vida; depressão materna; regulação emocional.
\end{abstract}

\section{ABSTRACT \\ Coping and Emotional Regulation in Children of Depressed Mothers}

The current study was designed to compare negative life events, as well as coping and emotional regulation strategies among children whose mothers had depression to those whose mothers had no psychiatric history. Forty children (boys and girls), ranging in age from 7 to 12 years with at least average levels of intellectual abilties participated in the study. Children were divided into two groups: G1-Maternal depression; and G2-no psychiatric history. Individual evaluations were made using Raven and the Negative Life Events Interview. Interviews were transcribed and coping and emotional regulation strategies were classified by two independent raters (agreement of 0.81 and 0.89 , respectively), based on previously determined categories. The data were compared using a MannWhitney $U$ test $(p \leq 0.05)$. No differences were found between the groups regarding events and coping toward stressors related with diseases and accidents. Greater use of passive waiting as an emotional regulation strategy towards everyday events was observed in G1. Data analysis showed that the groups were similar in terms of life experiences. In addition, children whose mothers were depressed used an adaptive effort strategy to cope with stressors brought about by negative life events.

Keywords: coping; life events; maternal depression; emotional regulation.

A depressão materna tem sido considerada uma situação pouco favorecedora do desenvolvimento infantil, configurando-se como um evento estressante para o cotidiano das crianças (Goodman \& Gotlib, 1999; Langrock, Compas, Keller, Merchant \& Copeland, 2002). As características próprias do quadro depressivo influenciam as interações mãe/criança e o ambiente familiar de forma a torná-lo estressante, o que se manifesta pela presença de comportamentos negativos e imprevisíveis, pela excessiva irritabilidade e nas práticas educativas, por disciplina inconsistente e baixa freqüência de comportamentos de suporte e ainda, a presença freqüente de relações maritais conflituosas e de insatisfação conjugal que favorecem um ambiente 
familiar cronicamente estressante (Goodman \& Gotlib, 1999; Langrock e cols., 2002). Nesse sentido, Armenta, Petterson, Verdugo e Ruiz (2004), com base em um estudo realizado com 150 mães mexicanas, que investigou a relação entre os níveis de depressão materna, as práticas das mães com seus filhos e os castigos físicos empregados contra eles, observaram que quanto maior o nível de depressão da mãe, maior a utilização de práticas punitivas com seus filhos.

Para as crianças, a depressão materna tem sido associada a prejuízos acadêmicos, a menor suporte dos amigos, a menor satisfação com a vida, a mais problemas de comportamento e utilização de programas de saúde mental, à presença de mais estressores cotidianos e ainda para os adolescentes, a maior risco de suicídio (Lewinson, Olino \& Klein 2005). Com relação especificamente às crianças em idade escolar Goodman e Gotlib (1999) chamam a atenção para a possibilidade de a depressão materna afetar o desenvolvimento de habilidades em diversos domínios, como o acadêmico e o de competência social, expressos por baixos níveis de auto-estima e altos níveis de problemas de comportamento. Os referidos autores destacaram ainda que as mães depressivas, quando comparadas às mães não depressivas, apresentam um padrão afetivo atípico no relacionamento com seus filhos, sendo apontadas como menos responsivas aos estados emocionais das crianças e menos atentas às manifestações afetivas destes, tendendo a manifestarem mais sentimentos de raiva e de tristeza do que afetos considerados mais positivos.

Segundo Silk, Shaw, Skuban, Oland e Kovacs (2006), as mães que experimentam desordens de humor apresentam dificuldades na regulação e na socialização de suas emoções, possivelmente como resultado de prejuízos em seu próprio desenvolvimento emocional, faltando-lhes as habilidades necessárias para ensinar e servir como modelo ou ainda reforçar meios mais adaptativos de modulação das emoções em seus filhos. No entanto, apesar de a depressão materna estar associada a condições reconhecidas de vulnerabilidade ao desenvolvimento das crianças, faz-se necessário considerar que o impacto de tal situação pode ser variável, na dependência da capacidade de enfrentamento das crianças frente aos eventos adversos de vida.

Os eventos de vida são as situações cotidianas, presentes na vida das pessoas ao longo de seu desenvolvimento, que podem atuar de forma tanto a facilitar, quanto a dificultar esse processo (Pereira, 2001). Para que um determinado evento seja considerado estressante, segundo a referida autora, este deve passar pela avaliação do indivíduo e ser julgado como algo que supera as suas capacidades de resolvê-lo. Tais situações podem envolver catástrofes como a perda de pais, de pessoas queridas, ou mesmo situações relacionadas a acontecimentos cotidianos como a mudança de escola, a discórdia familiar, as dificuldades acadêmicas, entre outros. Nesse sentido, os eventos tanto podem favorecer satisfação e bem estar como podem constituir-se em uma fonte de estresse e de risco.

Entende-se por fatores de risco os eventos ou situações que podem prejudicar o desenvolvimento da criança, favorecendo o surgimento de dificuldades e problemas. Contrapondo-se aos fatores de risco, estão os fatores de proteção, os quais proporcionam um desenvolvimento mais saudável ao indivíduo, na medida em que se constituem em uma fonte de segurança e bem-estar (Yunes \& Szymanski, 2001).

Segundo Pereira (2001), frente às situações novas e aos acontecimentos do cotidiano que podem ser considerados estressantes, as pessoas utilizam estratégias de enfrentamento, ou coping, como forma de resolução de tais problemas. Entende-se por coping ou enfrentamento os esforços cognitivos e comportamentais, que as pessoas utilizam para lidar com as demandas internas ou externas, que surgem em situações estressantes e que são avaliadas como sendo uma sobrecarga aos seus recursos pessoais (Antoniazzi, Dell'Aglio \& Bandeira, 1998). Diante de situações estressantes, o indivíduo experimenta emoções desagradáveis e adota estratégias para diminuir tal sofrimento (Lisboa e cols., 2002).

Considera-se que o uso de estratégias eficazes de enfrentamento constitui-se em uma forma de lidar ou até mesmo de modificar uma situação estressante que a criança esteja enfrentando no seu desenvolvimento (Halpern, 2004). Nesse sentido, destaca-se a relação entre o empenho da criança em desenvolver estratégias e a eficácia destas como um fator de proteção ao seu desenvolvimento (Pereira, 2001). No que se refere às crianças filhas de mães depressivas a presença de estratégias eficazes de enfrentamento pode ser considerada um recurso de proteção frente às vulnerabilidades associadas à convivência com a depressão materna.

As estratégias de enfrentamento refletem os recursos de regulação emocional que permitem a modulação dos afetos frente às situações cotidianas. Nesse sentido, a regulação emocional pode ser entendida como a modulação de reações emocionais feita pelas pessoas, visando maior adaptação às situações que envolvem demandas contextuais e objetivos pessoais 
(Silk e cols., 2006). Com base em uma revisão da literatura sobre os processos de regulação das emoções, os referidos autores destacaram que a capacidade de auto-regular as emoções desenvolve-se gradualmente, desde a infância. Consideram que os problemas na regulação emocional têm se relacionado a uma série de indicadores de ajustamento, como pobreza na competência social, depressão, ansiedade e problemas de comportamento. Os autores afirmaram ainda que prejuízo no desenvolvimento de estratégias de regulação emocional pode se constituir em fonte de vulnerabilidade para psicopatologias em crianças filhas de pais depressivos.

Tais autores consideram que as estratégias de regulação emocional agem sobre o desenvolvimento humano em diferentes domínios do funcionamento. No domínio cognitivo, as estratégias incluem a utilização de processos cognitivos como meio efetivo para o desvio da atenção, com conseqüente modulação do estresse. Esta habilidade de desviar a atenção de estímulos estressores está associada, segundo os referidos autores, à diminuição do estresse e a baixos níveis de sintomatologia internalizada e externalizada em crianças, podendo se configurar como um fator de proteção ao desenvolvimento infantil. No domínio comportamental, as estratégias incluem as ações da criança direcionadas para que se sintam melhores, como a manipulação do ambiente ou o engajamento em alguma atividade que proporcione distração ou alívio emocional. Destacam que o bom ajuste emocional das crianças está associado ao uso de estratégias comportamentais ativas e à redução do estresse.

Outros autores também estudaram as estratégias de enfrentamento utilizadas por crianças frente a situações estressantes, bem como suas tentativas de modulação de reações emocionais. Dell'Aglio e Hutz (2002), ao estudarem as estratégias de enfretamento utilizadas por crianças de oito a dez anos, constataram que evitar um problema pode ser uma maneira encontrada pela criança de lidar com a situação de estresse, prevenindo que o conflito se agrave. Dias, Vikan e Gravas (2000), em um estudo que investigou as estratégias de regulação emocional utilizadas por crianças brasileiras e norueguesas de quatro a nove anos de idade frente a situações que envolviam a apresentação de desenhos contendo cenas tristes, observaram que as crianças a partir de cinco e sete anos utilizavam estratégias cognitivas para a modulação de suas reações emocionais. Constataram também que as crianças brasileiras apresentavam a tendência de buscar mais o apoio dos pais como tentativa de regulação de suas emoções.

Partindo do pressuposto de que a depressão materna influencia o cotidiano de vida das crianças e está associada a estressores, configura-se o objetivo geral do estudo visando a caracterização dos eventos de vida negativos e as estratégias de enfrentamento e de regulação emocional apresentadas por crianças em idade escolar que convivem com mães com história de depressão, em comparação a crianças que convivem com mães sem história psiquiátrica.

\section{Método}

O estudo foi apreciado e aprovado pelo Comitê de Ética do Centro de Saúde Escola da FMRP - USP (Protocolo $\mathrm{n}^{\circ}$ 0011/CEP-CSE-FMRP-USP). A participação das crianças, bem como de suas mães foi voluntária, mediante a assinatura, por parte das mães, do Termo de Consentimento Livre e Esclarecido.

\section{Participantes}

Participaram estudo 40 crianças, de ambos os sexos (20 meninos e 20 meninas), com idades variando entre sete e 12 anos, com inteligência média inferior ou acima, residentes com suas mães biológicas. As crianças eram procedentes de famílias atendidas nos Núcleos do Programa de Saúde da Família do Centro de Saúde Escola da Faculdade de Medicina de Ribeirão Preto - USP, ou de famílias residentes na área compreendida pelos Núcleos.

As crianças participantes foram distribuídas em dois grupos, a saber: G1- formado por 20 crianças, cujas mães apresentavam história clínica psiquiátrica com diagnóstico de Depressão, sistematicamente avaliadas e G2- formado por 20 crianças, cujas mães não apresentavam história clínica psiquiátrica, recente ou pregressa, sistematicamente avaliadas.

A média de idade das crianças de G1 foi de nove anos e quatro meses (Desvio padrão - DP de 1 ano e 4 meses) e a das crianças de G2 foi de 10 anos (DP de 1 ano e 7 meses). Quanto à avaliação intelectual realizada com as crianças, a média e o DP dos resultados obtidos por G1 e G2, no Raven foi respectivamente percentil 64,20 (DP 24,81) e 66,70 (DP 23,28). Com relação à escolaridade, as crianças de G1 tinham uma média de 3,6 anos de escolaridade (DP de 1,27), enquanto as de G2 apresentavam média de 2,7 anos (DP de 1,26). As mães com história clínica de depressão apresentaram média de 6,55 anos de escolaridade (DP 3,63), enquanto que as mães sem história psiquiátrica apresentaram 
média de 8,45 anos de escolaridade (DP 4,47). Com base na análise estatística, não foram observadas diferenças significativas quanto às variáveis idade, nível intelectual das crianças e escolaridade das mães. Foi considerado critério de exclusão do estudo história de retardo mental, de doenças orgânicas crônicas ou deficiências sensoriais aparentes, bem como crianças com história de adoção ou ainda, aquelas que eram órfãs.

O processo de seleção das crianças participantes do estudo foi realizado tendo por base as informações de 1500 prontuários de mulheres/mães entre 25 e 40 anos de idade, com filhos na faixa etária de sete a 12 anos. Tais mulheres apresentavam diagnóstico clínico de Depressão, com história de internação psiquiátrica ou semi-internação nos últimos dois anos, sendo condição para a inclusão a remissão dos sintomas há pelo menos seis meses. As categorias do CID-10 (OMS, 1993) incluídas como diagnóstico psiquiátrico de Depressão foram: Depressão Moderada, Depressão sem Sintomas Psicóticos, Depressão com Sintomas Psicóticos e Depressão Recorrente. O diagnóstico de Depressão Leve ou como comorbidade de outras doenças foi considerado critério de exclusão do estudo.

As mães dos dois grupos foram avaliadas sistematicamente por meio da Entrevista Clínica Estruturada para o DSM-IV (SCID I) e DSM-III-R (SCID II), as quais foram traduzidas e adaptadas para o nosso meio por Del-Ben e cols. (2001). Tal avaliação foi feita tendo por objetivo excluir outros diagnósticos como comorbidade para G1 e garantir a ausência de história psiquiátrica pregressa para o G2.

\section{Instrumentos e Materiais}

Matrizes Progressivas Coloridas de Raven - Escala Especial: composta por 36 itens, divididos em três séries, tendo normas específicas para a avaliação do nível intelectual das crianças brasileiras (Angelini, Alves, Custódio \& Duarte, 1999).

Entrevista de Eventos Vitais Positivos e Negativos: trata-se de uma entrevista semi-estruturada que investiga eventos do cotidiano de crianças em idade escolar, os quais podem ser avaliados como positivos (por exemplo, ficar bem de saúde, conviver com animais, entre outros) ou negativos (ficar doente, receber advertências, entre outros). Foi elaborada conforme a proposição de Dell'Agio (2000), modificada por Bianchi (2002), que realizou um estudo de confiabilidade teste - reteste, com crianças que apresentavam dificuldades comportamentais, com 15 dias de intervalo, obtendo um coeficiente de 0,82 . A entrevista é composta por três partes, tanto para os eventos positivos, quanto para os negativos, a saber: relato espontâneo, relato dirigido e um jogo de classificação de cartões com a ordenação da importância dos eventos de vida.

O presente estudo apresentará, exclusivamente, dados relacionados ao relato dirigido sobre os 16 eventos de vida negativos, precedidos da seguinte instrução:

"Agora vou ler uma lista de coisas ruins que podem acontecer na vida de crianças da sua idade. Essas coisas também aconteceram com você, ultimamente? 1) Teve alguma coisa que você queria muito fazer e não pôde? 2) Ficou doente ou se machucou? 3) Alguém da sua família ficou doente ou sofreu acidente? 4) Teve problemas na escola (com as notas, amigos ou professores)? 5) Aconteceram brigas ou desentendimentos entre seus pais? 6) Aconteceram brigas ou desentendimentos na sua casa? 7) Brigou ou se desentendeu com algum amigo? 8) Sua família passou por dificuldades econômicas e sociais? 9) Sentiu medo? Ficou inseguro? 10) Passou por alguma situação de violência? 11) Aconteceram maus tratos, morte ou afastamento de algum animal de estimação? 12) Perdeu alguém querido? Morreu alguém com quem você tinha contato? 13) Foi ridicularizado ou desprezado? 14) Recebeu advertências/ punições? 15) Ficou afastado de algum familiar querido ou de alguém que gosta? 16) Aconteceram outras coisas ruins?"

Cada um dos eventos foi apresentado seguido de uma pausa, em que se aguardava a resposta da criança. Quando a criança confirmava a ocorrência de um evento negativo, era questionada sobre a maneira como o havia enfrentado, tendo por guia as seguintes questões: Por que você acha que aconteceu isso com você? Como você se sentiu? Como você reagiu? Você acha que poderia ter feito alguma coisa para evitar isso? Você contou com alguma ajuda para resolver isso? De quem? Como?

As entrevistas foram gravadas em áudio, tendo sido utilizados para tal gravador e fitas cassete.

\section{Procedimento}

Os participantes foram avaliados individualmente. Tal procedimento foi realizado por duas psicólogas e por uma estudante de psicologia, devidamente treinadas para a aplicação dos procedimentos utilizados. $\mathrm{Na}$ primeira sessão foi realizado um breve rapport e, em seguida, a aplicação individual do teste Matrizes Progressivas Coloridas de Raven. Em uma segunda ses- 
são, após um breve rapport, foi realizada a Entrevista de Eventos Vitais Negativos. Os 16 eventos negativos foram apresentados verbalmente, de forma pausada e quando a criança afirmava que o evento havia ocorrido consigo, era questionada sobre a forma como havia enfrentado tal situação.

\section{Tratamento dos dados}

O Raven foi codificado de acordo com as recomendações específicas da técnica. Quanto ao Relato Dirigido de Eventos de Vida Negativos, as entrevistas foram transcritas e as estratégias de enfrentamento e de regulação emocional frente aos eventos de vida negativos foram categorizadas.

Quanto ao Enfrentamento, as estratégias relatadas pelas crianças foram categorizadas de forma independente por duas avaliadoras, com concordância de 0,81 . As categorias previamente definidas foram elaboradas com base no proposto por Compas, Connor-Smith, Saltzman, Thomsen e Wadsworth (2001), incluindo o tipo de enfrentamento (voluntário ou involuntário), o envolvimento das crianças com as situações (engajamento ou desengajamento) e o tipo de controle utilizado (primário ou secundário).

Foram assim definidas: a) enfrentamento voluntário - refere-se a uma regulação intencional por parte do indivíduo, buscando solucionar um problema. Estratégia influenciada por capacidades cognitivas e comportamentais, exigindo maior maturidade da criança; b) enfrentamento involuntário - regulação alcançada através de processos biológicos involuntários (choro, por exemplo), sendo característico de idades precoces do desenvolvimento infantil; c) enfrentamento de engajamento - respostas direcionadas à fonte de estresse ou às emoções e pensamentos que surgem em decorrência dele, caracterizando uma ação direta frente aos eventos e emoções; d) enfrentamento de desengajamento - refere-se às respostas direcionadas para o distanciamento do estressor, englobando comportamentos relacionados ao afastamento e à negação do evento; e) controle primário - ação direta sobre o evento na tentativa de solucionar o problema ou regular a expressão emocional que surge em decorrência do estressor; f) controle secundário - ação indireta ou rearranjo frente ao estressor, englobando adaptação do indivíduo ao ambiente, o que envolve aceitação ou reestruturação cognitiva.

Com relação à Regulação Emocional, foram categorizados os mecanismos utilizados pelas crianças frente a dois tipos de situações, a saber: aquelas situações que englobavam estressores sobre os quais elas não tinham controle, como doenças ou acidente ocorridos com elas mesmas ou com familiares e estressores relacionados a situações cotidianas, como problemas na escola ou com amigos. Para tal, utilizou-se de quatro categorias, tendo por referência as proposições de Silk e cols. (2006), sendo elas: distração ativa, espera passiva, resolução direta e resolução indireta.

As categorias foram assim definidas: a) distração ativa - regulação buscada através de comportamentos que visam desviar a atenção do evento ou problema (tirar o foco da emoção negativa); b) espera passiva não-engajamento em qualquer ação em resposta ao evento ou problema, a criança mantém o foco de atenção no estressor, mas não tenta resolvê-lo; c) resolução direta - regulação da emoção através de uma ação direta que visa a resolução do problema, sem buscar auxílio externo; d) resolução indireta - regulação da emoção através do pedido de ajuda e suporte de outros, buscando através da ação do outro solucionar o problema. O procedimento de categorização foi realizado por duas avaliadoras independentes, obtendo-se nível de concordância de 0,89 .

Foi verificada a normalidade dos dados através do teste de Kolmogorov-Smirnov (KS), o qual evidenciou uma distribuição não normativa, sendo recomendado o emprego do Teste Não Paramétrico U de MannWhitney, para amostras independentes. Procedeu-se à comparação dos grupos, considerando-se a Média e o Desvio Padrão dos eventos de vida negativos e da ocorrência das estratégias de enfrentamento e de regulação emocional, adotando-se o nível de significância de $\mathrm{p} \leq 0,05$.

\section{RESULTADOS}

Na comparação quanto à ocorrência das situações relativas aos Eventos de Vida Negativos apresentadas no Relato Dirigido, não foram observadas diferenças estatisticamente significativas entre os grupos. No entanto, mesmo não atingindo o nível de significância, foram observadas algumas particularidades. As crianças de G1 responderam, com maior média a ocorrência de situações relativas a: não poder fazer algo $(\mathrm{G} 1=0,90$; $\mathrm{G} 2=0,75)$, familiar doente $(\mathrm{G} 1=0,65 ; \mathrm{G} 2=0,45)$, problemas na escola $(\mathrm{G} 1=1,05 ; \mathrm{G} 2=0,70)$, brigas dos pais $(\mathrm{G} 1=0,50 ; \mathrm{G} 2=0,30)$, brigas em casa $(\mathrm{G} 1=0,75$; $\mathrm{G} 2=0,55)$, dificuldade econômica $(\mathrm{G} 1=0,35 ; \mathrm{G} 2=0,30)$, sentir medo $(\mathrm{G} 1=0,45 ; \mathrm{G} 2=0,25)$, morte ou afastamento de animais $(\mathrm{G} 1=0,50 ; \mathrm{G} 2=0,30)$, ser ridicularizado $(\mathrm{G} 1=0,10 ; \mathrm{G} 2=0,00)$, ficar afastado de alguém querido $(\mathrm{G} 1=0,50 ; \mathrm{G} 2=0,30)$ e também, relataram 
uma maior média de situações negativas $(\mathrm{G} 1=7,30$; $\mathrm{G} 2=5,80)$.

As crianças de G1 responderam com menor média de ocorrência quando comparadas às de $\mathrm{G} 2$, ainda que sem diferença significativa, às categorias relacionadas a: ficar doente ou sofrer acidente $(\mathrm{G} 1=1,10 ; \mathrm{G} 2=1,15)$, brigas com amigos $(\mathrm{G} 1=0,10 ; \mathrm{G} 2=0,20)$, perder al- guém querido $(\mathrm{G} 1=0,20 ; \mathrm{G} 2=0,25)$, receber advertências e punições $(\mathrm{G} 1=0,10 ; \mathrm{G} 2=0,15)$ e sofrer violência $(\mathrm{G} 1=0,00 ; \mathrm{G} 2=0,15)$. As comparações dos grupos com relação aos modos de enfrentamento frente aos eventos negativos, diretamente investigados no relato dirigido, são apresentadas na Tabela 1.

TABELA 1

Média e Desvio Padrão dos Modos de Enfrentamento Apresentados Pelas Crianças de G1 e G2

\begin{tabular}{lcccccc}
\hline \multirow{2}{*}{ Modos de Enfrentamento } & Média & DP & Média & DP & p & Comparações \\
\hline Voluntário & 7,15 & 2,68 & 5,75 & 2,88 & 0,12 & Ns \\
Involuntário & 0,15 & 0,49 & 0,05 & 0,22 & 0,78 & Ns \\
Engajamento & 4,10 & 2,22 & 3,70 & 2,39 & 0,58 & Ns \\
Desengajamento & 3,05 & 1,82 & 2,05 & 1,57 & 0,12 & Ns \\
Primário & 2,35 & 1,66 & 2,45 & 1,82 & 0,86 & Ns \\
Secundário & 1,75 & 1,52 & 1,25 & 1,02 & 0,38 & Ns \\
\hline
\end{tabular}

Nota. Mann-Whitney U

${ }^{*} p \leq 0,050$

Frente às 16 situações de Eventos de Vida Negativos apresentadas, quanto ao tipo de enfrentamento utilizado, voluntário ou involuntário, não foram observadas diferenças estatisticamente significativas (Ns) entre os grupos, ainda que as crianças de G1 (crianças que convivem com a depressão materna) tenham apresentado maior média de utilização destes dois tipos de enfrentamento.

$\mathrm{O}$ envolvimento frente às situações foi categorizado quando da ocorrência de enfrentamento voluntário, frente a tais situações, não se observou diferença estatisticamente significativa entre os grupos. $\mathrm{O}$ mesmo foi observado quanto à utilização de enfrentamentos de engajamento ou desengajamento, ainda que as crianças de G1 tenham apresentado maior média de utilização destes tipos de envolvimento com as situações.

Quando da presença de enfrentamento voluntário e de envolvimento do tipo engajamento, foi categorizado o tipo de controle primário e secundário, não se observando diferença significativa, ainda que as crianças de G1 tenham apresentado menor média de utilização de controle primário, comparativamente à G2 (crianças que convivem com mães sem história psiquiátrica). As estratégias de regulação emocional utilizadas pelos grupos, frente a situações externas ao controle da criança, são apresentadas na Tabela 2.

TABELA 2

Média e Desvio Padrão das Estratégias de Regulação Emocional Utilizadas Pelas Crianças de G1 e G2 Frente a Estressores Relativos a Doenças e Acidentes

\begin{tabular}{lcccccc}
\hline & \multicolumn{3}{c}{ Estressores sobre os quais a criança não tem controle } \\
Estratégias de Regulação Emocional & \multicolumn{2}{c}{ G1 } & \multicolumn{2}{c}{ G2 } & p & Comparações \\
& Média & DP & Média & DP & & Ns \\
\hline Distração Ativa & 0,15 & 0,37 & 0,00 & 0,00 & 0,07 & Ns \\
Espera Passiva & 0,10 & 0,31 & 0,35 & 0,59 & 0,11 & Ns \\
Resolução Direta & 0,25 & 0,44 & 0,20 & 0,52 & 0,49 & Ns \\
Resolução Indireta & 0,60 & 0,60 & 0,70 & 0,80 & 0,83 & Ns \\
\hline Total & 1,10 & 0,64 & 1,25 & 1,16 & 0,95 & \\
\hline
\end{tabular}

Nota. Mann-Whitney U

${ }^{*} p \leq 0,050$

Frente às situações que envolvem a ocorrência de eventos estressores sobre os quais não se tem controle, como situações de doenças e acidentes ocorridos com as crianças ou com familiares, as crianças de G1 
(crianças que convivem com a depressão materna) e de G2 (crianças que convivem com mães sem história psiquiátrica) apresentaram médias próximas, sem diferenças significativas (Ns), quanto à utilização de estratégias de regulação emocional. No conjunto das Estratégias de Regulação Emocional utilizadas pelas crianças frente a tais situações, observou-se que mesmo sem diferença estatisticamente significativa, as crianças de G1 relataram, comparativamente à G2, maior média de utilização de estratégias classificadas como Distração Ativa e Resolução Direta. Ainda sem diferença significativa, observou-se que as crianças de G1 relataram menor média de utilização de estratégias classificadas como Espera Passiva e Resolução Indireta, comparativamente à G2. As estratégias utilizadas frente às situações cotidianas são apresentadas na Tabela 3.

\section{TABELA 3}

Média e Desvio Padrão das Estratégias de Regulação Emocional Utilizadas Pelas Crianças de G1 e G2 Frente a Estressores do Cotidiano

\begin{tabular}{lcccccc}
\hline \multirow{2}{*}{ Estratégias de Regulação Emocional } & \multicolumn{2}{c}{ Estressores cotidianos } & \multicolumn{2}{c}{ G2 } & & \multirow{2}{*}{ Comparações } \\
& Média & DP & Média & DP & $p$ & Ns \\
\hline Distração Ativa & $5,00 \mathrm{E}-02$ & 0,22 & 0,15 & 0,37 & 0,30 & G1>G2 \\
Espera Passiva & 0,45 & 0,69 & 0,10 & 0,31 & $0,05^{*}$ & Ns \\
Resolução Direta & 0,45 & 0,69 & 0,20 & 0,41 & 0,24 & Ns \\
Resolução Indireta & 0,15 & 0,37 & 0,15 & 0,37 & 1,00 & Ns \\
\hline Total & 1,10 & 0,97 & 0,60 & 0,75 & 0,08 & \\
\hline Nota. Mann-Whitney U & & & & & & \\
${ }^{*} p \leq 0,050$ & & & & & &
\end{tabular}

Frente às situações que envolviam estressores do cotidiano, como problemas na escola e com amigos, as crianças de G1 (crianças que convivem com a depressão materna) apresentaram, sem diferença estatisticamente significativa (Ns), maior média de utilização de estratégias de regulação emocional, comparativamente à $\mathrm{G} 2$ (crianças que convivem com mães sem história psiquiátrica). Na comparação do conjunto de estratégias de regulação emocional utilizadas pelas crianças, observou-se que as crianças de G1 relataram, com diferença estatisticamente significativa, maior média de utilização da estratégia classificada como Espera Passiva, comparativamente à G2. As crianças de G1 relataram ainda, mesmo que sem diferença significativa, maior média de utilização da estratégia Resolução Direta e menor média de utilização da estratégia classificada como Distração Ativa.

\section{DISCUSSÃO}

Na comparação dos grupos quanto ao relato dirigido sobre eventos de vida negativos, não foram observadas diferenças estatisticamente significativas com relação aos eventos estressantes a que as crianças são expostas. Tal dado sugere que as crianças estão tendo experiências de vida semelhantes, a despeito da convivência com a depressão materna.
Quanto ao rol de situações consideradas como eventos de vida negativos, observou-se que as crianças que convivem com a depressão materna relataram, mesmo que sem diferença significativa, maior média de situações relacionadas a dificuldades no contexto familiar e dificuldades pessoais, além de maior média de situações negativas de uma maneira geral, o que denota que tais crianças estão vivenciando maior número de situações que podem ser consideradas estressantes. As crianças que convivem com a depressão materna mencionaram situações que envolviam não poder fazer alguma coisa que quisessem muito, doenças de familiares, conflitos dos pais e em casa, dificuldades econômicas, sentir medo e insegurança, caracterizando o ambiente estressante em que essas crianças estão inseridas, o que vai ao encontro das proposições e Langrock e cols. (2002).

Quando os dois grupos foram comparados com relação ao modo de enfrentamento das crianças frente aos eventos estressores, não foram observadas diferenças estatisticamente significativas, sugerindo semelhança entre os grupos quanto ao modo como respondem aos eventos adversos da vida, e a presença de maior média de utilização de enfrentamento voluntário, em comparação ao enfrentamento involuntário, caracteriza a tentativa de busca da solução para os problemas que estão enfrentando. Conforme relatado 
por Yunes e Szymanski (2001), os comportamentos de enfrentamento eficientes são capazes de diminuir o impacto dos fatores de risco na vida do indivíduo. Neste sentido, pode-se pensar que as crianças que convivem com mães depressivas no momento da avaliação, se mostraram com mais recursos para o enfrentamento das adversidades. Possivelmente o critério de inclusão de mães depressivas, sem sintomas há pelo menos seis meses, e com a última crise há no máximo dois anos, pode ter favorecido a identificação de tais recursos de adaptação das crianças.

A presença de enfrentamento de engajamento de forma semelhante nos dois grupos corrobora os recursos das crianças que, independentemente da convivência com a depressão materna, estão direcionando suas respostas à fonte de estresse, numa tentativa de lidar com a situação estressora. Com sentido semelhante, destaca-se também a maior utilização de controle primário, que denota a presença de uma ação direta na tentativa de solucionarem os problemas que enfrentam e de regularem a sua expressão emocional frente às dificuldades.

Constata-se que as estratégias de enfrentamento utilizadas pelas crianças que convivem com a depressão materna e pelas crianças que convivem com mães sem história psiquiátrica, podem ser consideradas efetivas, apontando para a presença de recursos por parte das crianças de ambos os grupos no enfrentamento das situações adversas. Pode-se pensar que as crianças de $\mathrm{G} 1$, a despeito da convivência com a depressão materna, estariam de acordo com o exposto por Halpern (2004), tentando lidar e até mesmo modificar essas situações estressantes a que estão expostas. Ainda, segundo Pereira (2001), há uma relação entre a utilização de estratégias de enfrentamento eficazes, o controle satisfatório do estresse e o sucesso no desenvolvimento infantil. Nesse sentido, para as crianças de G1, a utilização de estratégias de enfrentamento eficientes frente às adversidades de vida a que estão expostas pode estar funcionando como um importante fator de proteção ao seu desenvolvimento.

No que se refere à regulação emocional, apesar de os grupos apresentarem comportamento semelhante frente a situações que fogem ao controle, observou-se que as crianças que convivem com a depressão materna apresentaram mais estratégias direcionadas à resolução dos problemas, principalmente buscando a ajuda de outras pessoas, o que corrobora os achados de Dell'Aglio e Hutz (2002) de que as crianças tendem a buscar auxílio de adultos quando estão em dificuldades. Observou-se ainda, a presença de estratégias que visavam desviar o foco de atenção da situação estressora, pode-se pensar que tal regulação funcionaria como uma fonte de proteção.

As crianças que convivem com a depressão materna poderiam estar se poupando do contato com a ansiedade associada a tal situação, o que sugere recurso adaptativo frente à situação adversa de vida que foge ao seu controle. Este tipo de comportamento em que as crianças buscam desviar a atenção da situação estressora foi identificado no estudo de Dell'Aglio e Hutz (2002) com crianças provenientes de uma amostra escolar, aparentemente sem problemas identificados. Os autores consideraram que as crianças nesse período de desenvolvimento, apesar de já terem consciência de seus estados emocionais, ainda não desenvolveram a plena capacidade para auto-regular suas emoções. Apontaram para a hipótese de que as crianças consideram os estressores que ocorrem com adultos como incontroláveis, optando assim, por não tentar resolver o problema.

Em um estudo realizado por Lisboa e cols. (2002), que avaliou o enfrentamento de crianças que sofreram violência doméstica frente a situações estressantes na escola, os autores observaram que tais crianças utilizavam estratégias chamadas de "inação", ou seja, não faziam nada frente a problemas com professores, os quais eram considerados como situações que fugiam de seu controle pessoal. Embora no estudo em questão o contexto de risco seja diverso, a exemplo das crianças do estudo de Lisboa e cols. (2002), as crianças do presente estudo também estão expostas à situação que foge ao seu controle, contudo, reagem de forma diversa, desviando o foco de atenção da situação estressora, o que pode ser considerado um fator de proteção ao seu desenvolvimento.

Frente aos eventos de vida relacionados a estressores do cotidiano, observou-se semelhança nos dois grupos quanto às estratégias de regulação emocional, com exceção da espera passiva, mais presente em G1, caracterizando a ausência de tentativa de resolução do problema e a manutenção do foco da atenção na situação estressora. Tal dado guarda relação com os problemas enfrentados no cotidiano escolar pelas crianças de G1, que referiram eventos relacionados a dificuldades com professores, conflitos e discussões com amigos e problemas com notas, como situações difíceis de resolverem. Nesse sentido os dados do presente estudo diferem dos achados de Dell'Aglio e Hutz (2002), segundo os quais, frente a situações de problemas com os pares, as crianças tendem a consi- 
derá-los como possíveis de serem resolvidos por meio da utilização de estratégias de resolução do problema.

A análise de tais dados sugere que as crianças que convivem com a depressão materna podem estar experimentando dificuldades em regular as próprias emoções frente a tarefas de socialização, que envolvem situações cotidianas comuns na vida de crianças neste período de desenvolvimento em que elas se encontram. Este tipo de funcionamento estaria corroborando as proposições de Silk e cols. (2006) quanto aos problemas apresentados por filhos de mães depressivas com relação à regulação de suas manifestações emocionais no cotidiano e as proposições de Goodman e Gotlib (1999) quanto à presença de habilidades sociais inadequadas e dificuldades no contato interpessoal. Nesse sentido, pode-se pensar que as crianças que convivem com mães com história de depressão parecem saber lidar melhor com situações que independem do seu controle, do que com situações comuns do cotidiano, o que pode ser relacionado ao aprendizado prévio em decorrência da convivência com a depressão materna.

Por outro lado, ao se detectar a presença de recursos de enfrentamento positivos neste grupo de crianças que convivem com a depressão materna, faz-se necessário valorizar tal potencial, sem perder de vista a necessidade de se oferecer suporte para tal grupo, que em função das características recorrentes da depressão, estará exposto a novos estressores que por sua vez, demandarão novos esforços adaptativos por parte dessas crianças.

Considera-se que o presente estudo contribui para a identificação e classificação sistemática dos modos de enfrentamento e regulação emocional de crianças em idade escolar, que convivem com a depressão materna. Contudo, o mesmo tem um caráter exploratório, em função da amostra de conveniência com número reduzido de participantes, o que limita o alcance dos dados, não permitindo, inclusive, comparações quanto ao gênero. Destaca-se ainda que o delineamento transversal adotado permite apenas a constatação do padrão de enfrentamento presente em um dado momento na vida destas crianças, não considerando o contínuo das manifestações. Outro ponto a ser comentado diz respeito à ausência de avaliação sistemática de outros estressores no cotidiano de vida das crianças, o que pode ter influenciado, inclusive, a forma de enfrentamento das crianças do grupo de comparação. Tal questionamento coloca em evidência a presença de um estressor reconhecido como a doença mental da mãe em contraste com outros estressores, por vezes não tão explícitos, mas que podem estar influenciando a vida cotidiana das crianças. Sugere-se que em novos estudos tal questão seja explorada de forma sistemática, levantando com as famílias a presença de múltiplos estressores, já que mais que um fator isolado, a combinação dos mesmos pode ter influência para o desenvolvimento infantil, o que também se aplica aos fatores de suporte que podem favorecer o enfrentamento das adversidades.

\section{REFERÊNCIAS}

Angelini, A. L., Alves, I. C., Custódio, E. M., Duarte, W. F., \& Duarte, J. L. (1999). Manual das matrizes progressivas coloridas de Raven: Escala especial. São Paulo: Centro Editor de Testes e Pesquisas em Psicologia.

Antoniazzi, A. S., Dell'Aglio, D. D., \& Bandeira, D. R. (1998). O conceito de coping: Uma revisão teórica. Estudos de Psicologia, 3(2), 273-294.

Armenta, M. F., Petterson, M. S., Verdugo, V. C., \& Ruiz, I. C. (2004). Parental styles and harsh parenting in a sample of mexican women: A structural model. Revista Interamericana de Psicologia, 38(1), 61-72.

Bianchi, S. H. (2002). Eventos de vida, auto-eficácia e autoconceito de crianças com dificuldades comportamentais. Dissertação de Mestrado não publicada, Departamento de Psicologia e Educação da Faculdade de Filosofia, Ciências e Letras de Ribeirão Preto, Universidade de São Paulo, Ribeirão Preto.

Compas, B. E., Connor-Smith, J. K., Saltzman, H., Thomsen, A. H., \& Wadsworth, M. (2001). Coping with stress during childhood and adolescence: Problems, progress and potential in theory and research. Psychological Bulletin, 127(1), 87-127.

Dell'Aglio, D. D. (2000). O processo de coping, institucionalização e eventos de vida em crianças e adolescentes. Tese de Doutorado não publicada, Instituto de Psicologia, Universidade Federal do Rio Grande do Sul, Porto Alegre.

Dell'Aglio, D. D., \& Hutz, C. S. (2002). Estratégias de coping e estilo atribucional de crianças em eventos estressantes. Estudos de Psicologia, 7(1), 5-13.

Del-Ben, C. M., Vilela, J. A. A., Crippa, J. A., Hallak, J. E. C., Labate, C. M., \& Zuardi, A. W. (2001). Test-retest reliability of the Structured Clinical Interview for DSM-IV - Clinical Version (SCID-CV) translated into portuguese. Revista Brasileira de Psiquiatria, 23(3), 156-159.

Dias, M. G. B. B., Vikan, A., \& Gravas, S. (2000). Tentativa de crianças em lidar com as emoções de raiva e tristeza. Estudos em Psicologia, 5, 49-70.

Goodman, S. H., \& Gotlib, I. H. (1999). Risk for psychopathology in the children of depressed mothers: A developmental model for understanding mechanisms of transmission. Psychological Review, 106(3), 458-490.

Halpern, L. F. (2004). The relations of coping and family environment to preschoolers' problem behavior. Journal of Applied Developmental Psychology, 25(4), 399-421.

Langrock, A. M., Compas, B. E., Keller, G., Merchant, M. J., \& Copeland, M. E. (2002). Coping with the stress of parental de- 
pression: Parent's reports of children's coping, emotional and behavioral problems. Journal of Clinical Child and Adolescent Psychology, 31(3), 312-324.

Lewinson, P. M., Olino, T. M., \& Klein, D. N. (2005). Psychosocial impairment in offspring of depressed parents. Psychological Medicine, 35, 1493-1503.

Lisboa, C., Koller, S. H., Ribas, F. F., Bitencourt, K., Oliveira, L., Porciúncula, L. P., \& De Marchi, R. B. (2002). Estratégias de coping de crianças vítimas e não vítimas de violência doméstica. Psicologia: Reflexão e Crítica, 15(2), 345-362.

Organização Mundial de Saúde (1993). Classificação de transtornos mentais e de comportamento da CID-10 (D. Caetano, Trad.). Porto Alegre: Artes Médicas.

Pereira, A. M. S. (2001). Resiliência, personalidade, stress e estratégias de coping. Em J. Tavares (Org.), Resiliência e educação (pp. 77-94). São Paulo: Cortez.
Silk, J. S., Shaw, D. S., Skuban, E. M., Oland, A. A., \& Kovacs, M. (2006). Emotion regulation strategies in offspring of childhood-onset depressed mothers. Journal of Child Psychology and Psychiatry. 47(1), 69-78.

Yunes, M. A. M., \& Szymanski, H. (2001). Resiliência: Noção, conceitos afins e considerações críticas. Em: J. Tavares (Org.), Resiliência e educação (pp. 13-42). São Paulo: Cortez.

Recebido: 12/12/2006

Última revisão: 14/11/2007 Aceite final: 01/12/2007

Notas:

${ }^{1}$ Apoio: CNPq.

Sobre as autoras:

Juliana Lopes: Psicóloga, graduada pela Faculdade de Filosofia, Ciências e Letras de Ribeirão Preto - USP

Sonia Regina Loureiro: Professora do Departamento de Neurologia, Psiquiatria e Psicologia Médica - Faculdade de Medicina de Ribeirão Preto - USP

Endereço para correspondência: Sonia Regina Loureiro - Rua Anita Garibaldi, 1419 -CEP 14085-480 - Ribeirão Preto - SP

Endereço eletrônico: srlourei@fmrp.usp.br 